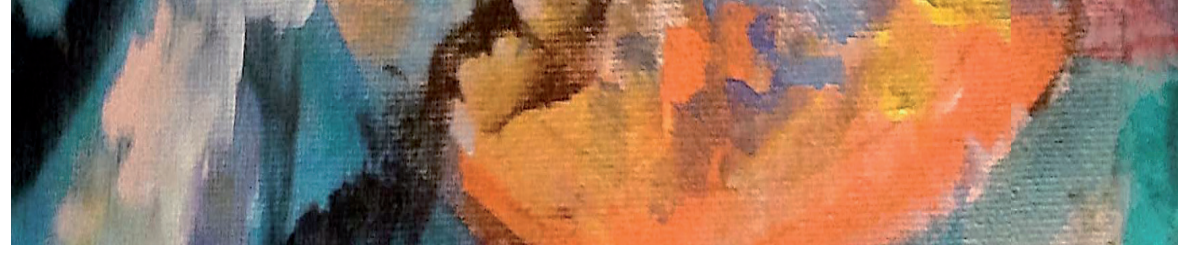

Entreculturas 11 (2021) pp. 120-130 — ISSN: 1989-5097

\title{
FRASEOLOGÍA EN EL LENGUAJE JURÍDICO: BINOMIOS Y MULTINOMIOS A TRAVÉS DEL CÓDIGO PENAL Y CÓDIGO CIVIL ITALIANO Y ESPAÑOL
}

\section{Phraseology in Legal Language: Binomials and Multinomials through the Italian and Spanish Penal Code and Civil Code}

\author{
(1) Rubén González Vallejo
}

Università degli Studi di Macerata

Recibido: 7 de octubre de 2020

Aceptado: 13 de enero de 2021

Publicado: 27 de febrero de 2021

\begin{abstract}
In this article we will deal with the phraseological units in legal language in order to make a profound contribution to the linguistic contrast between Spanish and Italian. Although there are recent studies on the application of phraseology in certain fields of applied linguistics, such as the teaching of second languages or translation, traditionally there has been a lack of contrast in the legal comparison of these units in the languages we are competent for. For this purpose, we will initially present one of the most accepted classifications of phraseology and then introduce which are the most present units in the phraseology specialized in the field of law. Afterwards, we will focus our attention on the binomials and multinomials, always providing in each case several examples extracted from the Italian and Spanish Criminal and Civil Codes through the AntConc terminology tool.
\end{abstract}

KEYWORDS: phraseology, binomials, multinomials, contrastive, criminal code.

\section{RESUMEN}

En el presente artículo trataremos las unidades fraseológicas en el lenguaje jurídico con el fin de aportar una profunda contribución a la contrastiva lingüística entre el español y el italiano. Si bien existen estudios recientes (Corpas Pastor, 2003; Higueras García, 2006; Timofeeva, 2012; Leal Riol 2013) sobre la aplicación de la fraseología en ciertos campos de la lingüística aplicada, como la enseñanza de segundas lenguas o la traducción, tradicionalmente se ha detectado una escasez contrastiva en la comparación jurídica de dichas unidades en los idiomas que nos competen. A tal propósito, inicialmente expondremos una de las clasificaciones más aceptadas de la fraseología para luego introducir cuáles son las unidades más presentes en la fraseología especializada en el campo del Derecho. Posteriormente, centraremos nuestra atención en los binomios y multinomios, proporcionando siempre en cada caso diversos ejemplos extraídos del Código Penal y del Código Civil italiano y español a través de la herramienta terminológica AntConc.

PALABRAS CLAVE: fraseología, binomios, multinomios, contrastiva, código penal. 


\section{INTRODUCCIÓN A LA FRASEOLOGÍA}

La importancia de la fraseología reside por un lado en su aceptación cotidiana, como su composición en fórmulas de cortesía, y por otro lado en un plano léxico más profundo al verse implicada en varios campos de la lingüística aplicada como la enseñanza de segundas lenguas o la lexicografía (Quiroga, 2006). De acuerdo con esta autora, y a causa de la divergencia terminológica existente para denominar a los diferentes elementos fraseológicos, adoptaremos la denominación más común, unidades fraseológicas. La clasificación de estas es especialmente cambiante debido al catálogo confeccionado por cada uno de los estudiosos ${ }^{1}$. Es menester y recomendable a este punto, antes de proseguir, despejar las incógnitas en torno a la ambigüedad terminológica de algunos conceptos que poseen una gran fijación interna en la frase como la locución, la colocación, la paremia y la unidad fraseológica.

Las locuciones son un conjunto de palabras, sintagmas estables que no aceptan ningún tipo de alteración por su fijación e idiomaticidad y pueden presentarse figuradamente al haber perdido su valor referencial, lo cual les permite adquirir diferentes significaciones en función de la situación (Ortíz, 2012). A causa del debate entre los estudiosos sobre incluir o no los compuestos sintagmáticos en la fraseología, como bien reflexiona Toledo y Martínez (2018) en su artículo sobre fraseología bilingüe, consideramos ambos como similares gracias a su nivel de cohesión interna. Ejemplos de locuciones serían «como una catedral», «ojo de buey» o «con vistas a».

Las colocaciones han sido encuadradas dentro de las unidades fraseológicas, y en palabras de Corpas (1998), son una «combinación estable de unidades léxicas formadas por al menos dos palabras gráficas, cuyo límite superior se sitúa en el nivel de la oración compuesta» (p. 167). Al igual que las locuciones, la idiomaticidad y fijación de las colocaciones es elevada en los diferentes contextos comu-

1 A este respecto, apréciense los estudios sobre fraseología de los siguientes autores destacados: Corpas (1996;1998), Castillo (1997), Koike (2001) y García Page (2008). nicativos que afrontamos cada día y ejemplos de ello serían en el lenguaje jurídico «prestar auxilio/juramento», «emitir fallo» o «dictar sentencia».

Las paremias, conocidas también como dichos o refranes, no son de fácil clasificación a causa de la falta de nitidez entre estas y las unidades lingüísticas, pues no todos los estudiosos las consideran parte de la fraseología. Las características que deben poseer son «el ser un enunciado breve, sentencioso, consabido, de forma fija y con características lingüísticas propias» (Sevilla, 1993, p. 15). Un ejemplo estaría constituido por el refrán «quien hace la ley, hace la trampa».

Por último, y en una relación de hiperonimia con las anteriores encontramos las unidades fraseológicas, que son una sucesión mínima de dos palabras caracterizada por una estabilidad, lexicalización e idiomaticidad, además de la posibilidad de presentar un «significado denotativo literal y significado denotativo figurado o traslaticio» (Sciutto, 2005, p. 505). Ejemplo de ello sería «lo mejor y lo peor» o «sin pies ni cabeza». En cuanto a su clasificación, nos guiaremos por la presentada por Koike (2001) y que divide estas unidades en simples y complejas. Dentro de las simples, se pone de manifiesto la importancia de las colocaciones sustantivo-verbo y sustantivo-adjetivo y se evidencian dos clasificaciones: las colocaciones léxicas y las funcionales. Las primeras abarcan las colocaciones sustantivo-verbo (compuestas por un verbo, un sustantivo y un sintagma que custodian su significado léxico, como en «alimentar rencor» o una «belleza incomparable») y las colocaciones sustantivo-adjetivo, en donde este último retiene su significado léxico como en "pelo ondulado». Cabe destacar la flexibilidad de algunos adjetivos que pueden mantener con ciertos sustantivos su significado léxico y con otros su significado lexical, «así, un susto mortal es un gran susto, pero un veneno mortal es aquel veneno que mata» (Quiroga, 2006). Por su parte, las funcionales se encuentran cuando el verbo abandona su significado léxico y necesita un sustantivo con el que reforzar dicho significado, como en «herir sentimientos» o «acercarse a la perfección».

Las colocaciones complejas, en cambio, según la denominación de Koike (2001) cubren una unión de unidad 


\section{Rubén González Vallejo \\ Entreculturas 11 (2021) pp. 120-130}

léxica y unidad fraseológica como en los siguientes ejemplos: verbo + locución nominal («imponer una pena»), locución verbal + sustantivo («llevar a cabo un proyecto»), sustantivo + locución adjetival («mantener fuera del alcance de los niños») y adjetivo + locución adverbial («sordo como una tapia»).

\section{FRASEOLOGÍA JURÍDICA}

El lenguaje jurídico se postula como la expresión de la base prescriptiva de las normas, las cuales regulan los cambios que se producen en las diferentes comunidades, dotadas de un carácter arcaico y atemporal al recoger las características de los sistemas normativos nacionales que han perdurado en el tiempo. Pese a haber llevado a cabo programas de simplificación para la modernización de su lenguaje, su reticencia ante los procesos de redacción legislativa se hace latente en las disposiciones que actualmente se emanan, pues son asiduas las frases enrevesadas, las oraciones pasivas, el futuro de subjuntivo, la omisión del artículo, los anafóricos o la hipotaxis, entre otros. La fluctuación entre la lengua del derecho y la común se muestra con cierta intensidad al producirse un intercambio continuo de palabras, dado que esta última subyace en la comunicación especializada (Belvedere, 2016; Gotti, 1991). Su ámbito de especialidad conlleva una ardua transposición terminológica con conceptos fuertemente marcados culturalmente y de no fácil traducción. Es aquí donde la óptica de la (in) traducibilidad se ha dejado ver, al servicio de la ansiada equivalencia formal entre conceptos jurídicos, la cual cambiará en función de los destinatarios y de la naturaleza del documento.

Kjaer (2007) en su trabajo sobre los frasemas en los textos legales realiza una clasificación sobresaliente de la fraseología jurídica, compuesta por cinco categorías que se adhieren a las características que subyacen en el lenguaje jurídico. A continuación, se exponen en una tabla dichas categorías junto a ejemplos extraídos del Código Penal (CP) y del Código Civil (CC) español.
TABLA 1. Las categorías de la fraseología jurídica según Kjaer

\begin{tabular}{cc}
\hline $\begin{array}{c}\text { Multi-words-terms } \\
\text { ('términos poliléxicos') }\end{array}$ & $\begin{array}{c}\text { Medida cautelar (art. 339 CP), } \\
\text { representante legal (art. 147. iv CP) } \\
\text { patria potestad (art. 149. ii CP) }\end{array}$ \\
\hline Colocations ('colocaciones') & Dictar sentencia (art. 119 CP) \\
\hline Funktionsverbgefüge & Imponer una multa (art. 52. ii CP), \\
('construcciones con verbo & entrar en vigor (art. 2 CP) \\
\hline sinomials ('binomios') & Cargas y obligaciones (art. 986 \\
& CC) \\
\hline Legal phrasemes & De oficio, etc. (art. 58. ii CP) \\
\hline
\end{tabular}

Por su parte, Tabares (2016) realiza una clasificación de las unidades fraseológicas especializadas del derecho en tres niveles: cadenas gramaticales con valor preposicional y fórmulas adverbiales, construcciones verbonominales y textos formularios. En el primer nivel encontramos los elementos suboracionales, los cuales se sitúan entre el nivel de la palabra y el de la oración y pueden admitir pequeños cambios o permanecer inalterados. Algunos ejemplos estarían constituidos por «con arreglo a» (art. $8 \mathrm{CP}$ ), «en virtud de» (art. 3 CP) o «a instancia de» (art. 124 CP). Por otra parte, las fórmulas adverbiales compuestas por preposición más adjetivo hacen su aparición constantemente en el lenguaje jurídico, bajo formas como «a cuyo efecto» (art. 130. I. 5 CP), «en los términos previstos» (art. 270. VI CP), «con carácter privativo» (art. $1350 \mathrm{CC}$ ), etc. En el segundo nivel, también encuadrado como elemento suboracional, encontramos las construcciones verbonominales, que al poseer términos que pueden abarcar diferentes funciones en la frase engloban gran parte de las colocaciones destacadas en la literatura de especialidad. Por ello, se presentan como las más presentes y analizadas en el lenguaje jurídico por el tecnicismo que otorgan, como los casos de «otorgar el consentimiento» (art. 82. I CC), «revocar la suspensión» (art. 86. IV CP), «interponer querella/denuncia» (art. 305. IV CP), «dictar sentencia» (art. 119 CP), «estimar la de- 


\section{LA (IN)TRADUCIBILIDAD DEL PROTOTEXTO AUDIOVISUAL}

Entreculturas 11 (2021) pp. 120-130

manda» (art. $1801 \mathrm{CC}$ ), etc. El último nivel se encuadra en el marco «oracional o supraoracional, puesto que abarca desde enunciados fraseológicos hasta marcos (macro) textuales» (Tabares, 2016, p. 7). Son expresiones fijas que forman parte de la estructura del texto y que responden, en gran medida, al oscurantismo del lenguaje jurídico. A tal propósito, citamos como ejemplos cuando se detalla el veredicto del juez las frases «FALLA: ...]» y «Fallo. En atención a todo lo expuesto, el Tribunal Constitucional, por la autoridad que le confiere la Constitución de la Nación española, ha decidido estimar» (Sentencia núm. 126, 2019). Otro ejemplo sería la frase «Mediante providencia de fecha de [...], el Pleno de este Tribunal acordó admitir a trámite la cuestión planteada y, de conformidad con...» (Id.).

Por último, un aspecto de la fraseología jurídica que debemos tener en cuenta es la variación geográfica de la terminología. A este respecto, Tabares (2016) pone de manifiesto la divergencia terminológica existente entre los países hispanos que representan distintas alternativas para un mismo término, lo cual nos permite recordar la importancia que poseen los sistemas jurídicos al estar estrechamente relacionados no solo con la lengua, sino también con la cultura. Algunos ejemplos que expone son:

1. (Tentativa de delito $(\mathrm{ES})^{2} /$ Estado de tentativa (CR)/ En grado de tentativa (PA)

2. De forma unánime (ES)/ En forma unánime (CR)/ Por unanimidad (UY)

3. Proferir sentencia (PA)/ Proferir fallo (PA)/ Emitir fallo (UY)

4. Fundar un fallo (ES)/ Habilitar un fallo (UY)

5. Dar traslado (ES)/ Conferir traslado (UY)/ Correr traslado (CR)

6. FALLO (ES)/ Se declara... (CR)/ PARTE RESOLUTIVA (PA)/ FALLA (UY)

2 Las formas pertenecientes a la variedad del español del autor del presente trabajo, para su rápida identificación, se presentan subrayadas. Además, las siglas indicadas en los ejemplos se corresponden con los siguientes países: CR (Costa Rica), UY (Uruguay), PA (Paraguay) y ES (España).
A estos añadimos los detallados en trabajos anteriores en la ley medioambiental italiana núm. 68 del 22 de mayo de 2015 , en donde encontramos términos que en su traducción hacia el español pueden cambiar dentro de ese gran espectro conocido como hispanoamérica: el Codice di procedura penale en Italia se correspondería en España con la Ley de Enjuiciamiento Criminal, pero con el Código de Procedimiento penal en Colombia, Ecuador y Bolivia y con el Código procesal penal en Guatemala, Honduras y Costa Rica. Otro ejemplo sería el llamado dibattimento di primo grado que se suele traducir en España por vista oral, mientras que países como México y Guatemala muestran la locución debate de primer grado (González Vallejo, 2020).

\section{BINOMIOS Y MULTINOMIOS}

Malkiel (1959) resalta la definición de binomio como «la secuencia de dos palabras que pertenecen a la misma categoría de palabras, que comparten el mismo nivel sintáctico y que están normalmente unidas por un conector» (p. 113)3. Este sería el caso del binomio del art. 730 CC «abiertos y rezados», cuya posición sintáctica depende del sustantivo «testamentos». La relación entre los miembros de un binomio se antoja sólida y dependiente, pues si bien pueden no respetarse a nivel sinonímico (art. $725 \mathrm{CC}$ «copia del testamento o del acta»), lo hacen a nivel gramatical a través de la concordancia ad sensum que se crea con el elemento precedente como en el caso de «por días o por horas» (art. $561 \mathrm{CC}$ ), si bien raramente se omita el elemento de unión (art. $1265 \mathrm{CC}$ «será nulo el consentimiento prestado por error, [por] violencia, [por] intimidación o [por] dolo»). Por otra parte, esta dependencia se deja ver incluso desde el punto de vista de la semántica, pues en el art. 145 bis CC «Juez o tribunal» se crea una relación hiperonímica de este último con aquel, pues el tribunal es el conjunto de jueces, si bien exista el tribunal unipersonal en contraposición al colegiado. Asimismo, son fórmulas a las que se recurre gracias a su brevedad, su precisión y por su

3 La traducción del inglés pertenece al autor del presente trabajo. 
fácil carácter de memorización (Andrades, 2013). Por ello, han sido elementos muy utilizados en la tradición oral por ser de ágil reproducción al presentar características como la aliteración («sol y sombra»), la rima («Levante y Poniente») o la repetición («más y más»). Dichos elementos mantienen un vínculo que garantiza una economía en la frase (Luque 2017) y pueden estar motivados por meras razones lingüísticas o por la experiencia enciclopédica: mientras la primera tiene que ver con procesos como el de rima (art. 355 CPI «all'armamento o all'equipaggiamento»), el segundo refleja una proposición (art. 314 CPI «Il pubblico ufficiale e l'incaricato di un pubblico servizio»).

Asimismo, Vázquel y del Árbol (2006) define los binomios como característicos del lenguaje jurídico, los cuales «dotan al texto de cierto carácter enfático, retórico y “formulista” (p. 20). Esta autora detalla también las dos tendencias que recogen las técnicas de traducción para los binomios, pues si bien unas abogan por simplificar las expresiones, otras por respetar las estructuras para fortalecer el carácter del texto. Recomienda además tener en cuenta las varias opciones al alcance del traductor, pues no solo se traducen palabras, sino que también sistemas jurídicos diferentes con el objetivo de que el texto produzca las mismas reacciones a efectos legales. A tal respecto, piénsese incluso en los mismos binomios equivalentes a partir de códigos normativos de diferentes países que comparten la misma lengua, como los resaltados por Macías (2015: 225) procedentes de la Constitución Mexicana en contraposición con la correspondencia en el sistema español, como «vivienda digna y decorosa» («vivienda digna» en España); «el varón y la mujer» («los españoles»); «la Nación Mexicana es única e indivisible» («la Constitución se fundamenta en la indisoluble unidad de la Nación española»). Este carácter constitucional ya pone de manifiesto su uso tradicional y duradero, pues su existencia se recogía ya en la época del Derecho Romano (Del Río Zamudo, 2018) y se recurría a ellos por la exactitud que suponían (Frago, 1989).

Por su parte, Macías (2013) realiza una enumeración de las clasificaciones realizadas para los binomios por parte de varios autores, siendo casi siempre un elemento común las relaciones sinonímicas, antonímicas y de complementariedad. Cabe destacar que añadimos a las siguientes la relación hiperonímica que existe por ejemplo en binomios como «todos y cada uno»:

\begin{abstract}
Este autor [Malkiel (1959, pp. 125-129)] clasifica las expresiones binomiales según relación semántica que existe entre los componentes de la expresión: cuasisinonimia («seguridad y recaudo»); complementariedad mutua («vivienda y ajuar familiar»); oposición («aumento o disminución»); subdivisión o partes («meses o años»); consecuencia («compra y venta»). Gustafsson (1984: 133), igual que Malkiel, realiza una clasificación basada en las relaciones semánticas entre los términos y distingue: sinónimos («lugar o sitio»); antónimos («soltero o casado»), y complementarios («en tiempo y forma») [...] y, por último, aquellas que combinan algunas de las categorias gramaticales anteriores («juramento o bajo condición») (p. 215).
\end{abstract}

Por último, en ocasiones nos encontramos en los textos jurídicos con varios elementos relacionados por un conector con el mismo peso en la frase. Estas estructuras tradicionalmente en función del número de sus compuestos han recibido el nombre de trinomios, cuatrinomios, tetranomios, etc.; sin embargo, en este trabajo para más de dos elementos recurriremos al término multinomio. La definición de este en palabras de Gustafsson (1975) se delinea como «una enumeración de politérminos relacionada con la situación comunicativa» (p. 17) ${ }^{4}$.

Con todo, cabe destacar que la frecuencia de elementos simétricos en periodos extensos, y en ocasiones sinónimos e innecesarios, por ser redundantes y dar notas de ampulosidad, no es un fenómeno propio del lenguaje jurídico-administrativo. No sin razón, en la lengua común no es inusual escuchar locuciones como «tarde o temprano», «sano y salvo» o «ajo y agua».

4 La traducción del inglés pertenece al autor del presente trabajo. 


\section{LA (IN)TRADUCIBILIDAD DEL PROTOTEXTO AUDIOVISUAL}

Entreculturas 11 (2021) pp. 120-130

Esta flexibilidad compositiva crea no pocos problemas de traslación, ya que la dificultad de la traducción de los binomios reside en respetar las mismas características de la lengua de origen. Esta dificultad se agrava aún más en el proceso traductor por las características que poseen, esto es:

A. Fonético-fonológicas (recuérdense la aliteración y la rima anteriormente citadas).

B. Sintácticas, ya que están compuestos por una parte por conjunciones o preposiciones que presentan una irreversibilidad en su escritura, es decir, funciona con cierta regularidad la estructura «por sí o por otro» (art. 360 CC), pero no tanto «por otro o por sí». Por otra parte, en cambio, encontramos los que funcionan intercambiando sus componentes como en «Giudici ordinari e speciali» (art. 13 del Codice di Procedura penale)/ «Giudici speciali e ordinari».

C. Semánticas. Gracias a su poder semántico, confluyen relaciones sinónimicas como «con dolo o con colpa» (art. 1892 CCI), antonímicas como «adottante e adottato» (art. $436 \mathrm{CCI}$ ) y de complementariedad como «poteri e doveri» (art. $2491 \mathrm{CCI})$.

D. Por último, gramaticales (vid. las siguientes tablas 2 y 3 para conocer las categorías que pueden formar los binomios y multinomios).

Como estrategia de traducción ante tales elementos dependientes, y siempre en busca de la equivalencia que pueda proporcionarnos los efectos legales del texto fuente $\mathrm{u}$ otorgar un equivalente funcional en su defecto, Andrades (2013) propone las siguientes técnicas para afrontar la traducción de binomios en el lenguaje jurídico:

1. Equivalencia plena: nos encontramos ante dos binomios que cubren el mismo espectro semántico en ambos sistemas. Este es el caso de «diritti e doveri» (art. $300 \mathrm{CCI}$ ), que en español podría traducirse por el correspondiente «derechos y deberes» que encontramos, por ejemplo, en el art. 34. I de la L0 9/2011.
2. Simplificación: a diferencia del anterior no se detecta un binomio funcionante y se traduce por una de las dos partes o por una estructura ajena. Este es el caso que hemos podido encontrar en las diferentes traducciones del binomio «con premeditación y alevosía» al traducirse en italiano generalmente como premeditazione. El CP español prevé la alevosía con el agravante ideológico por el cual con un medio o con un instrumento se asegura la ejecución de una acción. Sin embargo, en el CPI (arts. 576 y 577) este concepto se recoge en el de premeditazione. Asimismo, su simplificación supondría dos beneficios: por una parte, promueve una adquisición más rápida del concepto y por otra, puede constituir una propuesta de traducción válida en la lengua meta. Para ello, el autor recomienda considerar las propuestas de simplificación de los binomios recogidas en el Plain Language Association.

3. Ausencia de equivalencia: la falta de correspondencia hace que se traduzca el binomio por un concepto o expresión con el objetivo de cubrir el mismo espectro semántico. A este respecto, el binomio «argomenti e temi» que encontramos en el art. 336 bis del CCI podría traducirse en español, vista la difícil relación de los usos en estas dos lenguas de argomenti (it.)/ argomento (esp.) y tema (it.)/tema (esp.), por 'argumentos', eludiendo uno de ellos por razones de (cuasi)sinonimia.

4. Calco estilístico: se puede traducir con un concepto o con un binomio a través del calco lingüístico por razones estilísticas. Este sería el caso, por ejemplo, del multinomio presente en el art. 334 del CPI, que no se vería reforzado jurídicamente si se condensaran las acciones. Estas rezan en italiano de la siguiente manera: «Chiunque sottrae, sopprime, distrugge, disperde o deteriora una cosa sottosposta a sequestro...», y en español podrían traducirse por «aquel que robe, elimine, destruya, pierda o deteriore un objeto embargado...». 


\section{Rubén González Vallejo \\ Entreculturas 11 (2021) pp. 120-130}

A continuación, y fruto del trasfondo teórico planteado sobre los binomios fraseológicos, nos proponemos presentar una tabla con algunos de los binomios detectados en los Código Penal (CP), Código Civil (CC), Código Penal italia- no (CPI) y Código Civil italiano (CCI) a través de la herramienta de concordancias AntConc, con el fin de analizar los resultados y otorgar una aportación más a los escasos estudios contrastivos entre el español y el italiano.

TABLA 2. La presencia de binomios en el lenguaje jurídico por categorías

\begin{tabular}{|c|c|c|}
\hline & ITALIANO & ESPAÑOL \\
\hline Sustantivo & $\begin{array}{l}\text { Termini e forme (art. } 38 \mathrm{CPI} \text { ), diritti e doveri (art. } \\
300 \mathrm{CCI} \text { ), argomenti e temi (art. } 336 \mathrm{CCI} \text { ), affari e } \\
\text { interessi (art. } 343 \mathrm{CCI} \text { ), titoli e valori (art. } 369 \mathrm{CCI} \text { ), } \\
\text { interdizione e inabilitazione (art. } 416 \mathrm{CCI} \text { ), computo } \\
\text { e decorrenza dei termini (art. } 14 \mathrm{CPI} \text { ), denominazio- } \\
\text { ne e classificazione (art. } 18 \mathrm{CPI} \text { ), delitti e contravven- } \\
\text { zioni (art. } 39 \mathrm{CPI} \text { ), atti e oggetti (art. } 529 \mathrm{CPI} \text { ) }\end{array}$ & $\begin{array}{l}\text { Riesgo e incumplimientos (art. } 31 \text { bis CP), beneficios e in- } \\
\text { centivos (art. } 33 \mathrm{CP} \text { ), libertad e indemnidad (art. 90, CP), } \\
\text { grado y extensión (art .72 CP), deberes y obligaciones } \\
\text { (art. } 83 \mathrm{CP} \text { ), naturaleza y efectos (art. } 73 \mathrm{CP} \text { ), atenuantes } \\
\text { y agravantes (art. } 66 \mathrm{CP} \text { ), deberes y obligaciones (art. } 83 \\
\mathrm{CP} \text { ), prohibiciones y deberes (art. } 83 \mathrm{CP} \text { ), penas y medi- } \\
\text { das (art. } 83 \mathrm{CP} \text { ), límites y garantías (art. } 89 \mathrm{CP} \text { ), pena y } \\
\text { concesión (art. } 90 \mathrm{CP} \text { ) }\end{array}$ \\
\hline Verbo & $\begin{array}{l}\text { dichiara o attesta (art. } 374 \text { bis CPI), aggravano o dimi- } \\
\text { nuiscono (art. } 118 \mathrm{CCI} \text { ), elidere o attenuare (art. } 163 \\
\mathrm{CPI} \text { ), danneggiare o distruggere (art. } 420 \mathrm{CP} \text { ) }\end{array}$ & $\begin{array}{l}\text { modificar o suspender (art. } 33 \mathrm{CP} \text { ), disuelva o suspenda } \\
\text { (art. } 539 \mathrm{CP} \text { ), revocará la suspensión y ordenará la ejecu- } \\
\text { ción (art. } 86 \mathrm{CP} \text { ), destituir o despoja (art. } 472 \mathrm{CP} \text { ), donar } \\
\text { o permutar (art. } 1635 \mathrm{CC)}\end{array}$ \\
\hline Adjetivo & $\begin{array}{l}\text { Scritta e motivata (art. } 30 \mathrm{CP} \text { ), espressa o tacita (art. } \\
120 \mathrm{CPI} \text { ), consumato o tentato (art. } 157 \mathrm{CPI} \text { ), puro e } \\
\text { semplice (art. } 485 \mathrm{CCI} \text { ), principali e accessorie (art. } 20 \\
\mathrm{CPI} \text { ), fisse e proporzionali (art. } 27 \mathrm{CPI} \text { ), dannose o } \\
\text { pericolose (art. } 62 \mathrm{CPI} \text { ), significativi e misurabili (art. } \\
452 \mathrm{CPI} \text { bis), estese o significative (art. } 452 \mathrm{CPI} \text { bis) }\end{array}$ & $\begin{array}{l}\text { Relevante y favorable (art. } 90 \mathrm{CP} \text { ), familiares y sociales } \\
\text { (art. } 90 \mathrm{CP} \text { ), físicas y económicas (art. } 80 \mathrm{CP} \text { ), económicas } \\
\text { y sociales (art. } 66 \text { bis CP), excesivos y desproporcionados } \\
\text { (art. } 83 \mathrm{CP} \text { ), oneroso o gratuito (art. } 460 \mathrm{CC} \text { ) }\end{array}$ \\
\hline Adverbio & $\begin{array}{l}\text { espressamente o tacitamente (art. } 155 \mathrm{CPI} \text { ), } \\
\text { congiuntamente o alternativamente (art. } 157 \mathrm{CPI} \text { ), } \\
\text { pubblicamente e intenzionalmente (art. } 404 \mathrm{CPI} \text { ) }\end{array}$ & $\begin{array}{l}\text { Pública e indebidamente (art. } 402 \text { bis CP), deliberada e } \\
\text { inhumanamente (art. } 22 \text { CP), total o parcialmente (art. } \\
301 \mathrm{CP} \text { ) }\end{array}$ \\
\hline Preposición & $\begin{array}{l}\text { Con dolo o con colpa (art. } 2600 \mathrm{CCI} \text { ), con o senza } \\
\text { autenticazione (art. } 2705 \mathrm{CCI} \text { ), in tutto o in parte (art. } \\
6 \mathrm{CPI} \text { ), a termini o a condizione (art. } 152 \mathrm{CPI} \text { ), per caso } \\
\text { fortuito o per forza maggiore (art. } 45 \mathrm{CPI} \text { ), per sé o per } \\
\text { altri (art. } 246 \mathrm{CPI} \text { ), per sé o per un terzo (art. } 316 \mathrm{CPI} \text { ) }\end{array}$ & $\begin{array}{l}\text { En todo o en parte (art. } 472 \text { CP), con ánimo de lucro y } \\
\text { con conocimiento (art. } 298 \mathrm{CP} \text { ), por sí o por otro, (art. } 360 \\
\text { CC), por su mandatario y por un tercero (art. } 439 \text { CC), por } \\
\text { la ley o por la voluntad (art. } 536 \text { CC), por sí o por medio } \\
\text { (art. } 630 \text { CC), a costa o en sustitución (art. } 1346 \text { CC) }\end{array}$ \\
\hline
\end{tabular}




\section{LA (IN)TRADUCIBILIDAD DEL PROTOTEXTO AUDIOVISUAL}

Entreculturas 11 (2021) pp. 120-130

TABLA 3. La presencia de multinomios en distintas categorías

\begin{tabular}{|c|c|c|}
\hline & ITALIANO & ESPAÑOL \\
\hline Sustantivo & $\begin{array}{l}\text { Contraffazione, alterazione o uso (art. } 473 \mathrm{CPI} \text { ), violazione, } \\
\text { sottrazione e soppressione (art. } 616 \mathrm{CPI} \text { ), per effetto di } \\
\text { amnistia, indulto o grazia (art. } 184 \mathrm{CPI} \text { ), soppressione, } \\
\text { falsificazione o sottrazione (art. } 255 \mathrm{CPI} \text { ), violenza, } \\
\text { minaccia o inganno (art. } 294 \mathrm{CPI} \text { ), para su expedici' }\end{array}$ & $\begin{array}{l}\text { patrimonio, ingresos, obligaciones y cargas familiares } \\
\text { y demás circunstancias personales (art. } 50 \mathrm{CP} \text { ), orga- } \\
\text { nizaciones y grupos terroristas y delitos de terrorismo } \\
\text { (art. } 76 \mathrm{CP} \text { ), naturaleza, circunstancias y gravedad del } \\
\text { delito (art. } 89 \mathrm{CP} \text { ), identificación, captura y procesa- } \\
\text { miento de responsables (art. } 90 \mathrm{CP} \text { ), producción, re- } \\
\text { colección y conservación (art. } 356 \mathrm{CC} \text { ), para su expe- } \\
\text { dición o distribución o puesta en circulación (386 CP) }\end{array}$ \\
\hline Verbo & $\begin{array}{l}\text { Chiunque sottrae, sopprime, distrugge, disperde o } \\
\text { deteriora (art. } 334 \mathrm{CPI})\end{array}$ & $\begin{array}{l}\text { Aprovechan, venden o permutan (art. } 424 \mathrm{CC} \text { ), dero- } \\
\text { gar, suspender o modificar (art. } 472 \mathrm{CP} \text { ) }\end{array}$ \\
\hline Adverbio & $\begin{array}{l}\text { Affettivamente, psicologicamente o economicamente } \\
\text { (art. } 90 \text { quarter CPPI) }\end{array}$ & $\begin{array}{l}\text { Válida, libre, espontánea y expresamente emitido (art. } \\
155 \text { CC) }\end{array}$ \\
\hline Preposición & $\begin{array}{l}\text { Per dolo o per colpa o per delitto preterintenzionale (art. } \\
42 \mathrm{CPI} \text {, per terra, per acqua o per aria (art. } 355 \mathrm{CPI} \text { ), } \\
\text { con violenza, minaccia o suggestione (art. } 579 \mathrm{CPI} \text { ), con } \\
\text { denuncia, querela, richiesta o istanza (art. } 367 \mathrm{CPI} \text { ) }\end{array}$ & $\begin{array}{l}\text { Con Gobiernos extranjeros, con sus agentes o con } \\
\text { grupos (art. } 592 \mathrm{CP} \text { ) }\end{array}$ \\
\hline
\end{tabular}

Como se desprende de lo detallado, predominan mayoritariamente los binomios compuestos por sustantivos, si bien se encuentran otros formados por categorías como verbos, adjetivos, adverbios o preposiciones. La razón se encuentra en la nominalización a la que tiende el lenguaje jurídico, la cual permite esconder el actor y otorgar un carácter más oficial a la comunicación, pues se trata de normas que se emanan de forma prescriptiva para el acatamiento de las leyes por parte de la comunidad. En el caso de la morfología verbal, encontramos el presente o el infinitivo en italiano al ser las formas que más resaltan la percepción jurídica de la acción (Mortara Garavelli 2001), evitando el carácter hipotético que proporcionan las formas de futuro o de subjuntivo recurrentes en español, como el art. $148 \mathrm{CP}$, que contiene dos binomios con fu- turo de subjuntivo, «fuere o hubiere sido» y «estuviere o hubiere estado». En el caso de los adjetivos, encontramos la ambigüedad que tanto subyace en el lenguaje jurídico con el fin de hacer perdurar las leyes y abrir las puertas a la voluntad de quien juzga para poder considerar así todas las casuísticas legales posibles y circunstancias no previstas. En el caso de los adverbios, nos encontramos ante una asimetría morfológica al añadir en italiano en ambos miembros del binomio el sufijo -mente, mientras que el español requiere solamente la presencia del sufijo en el segundo término. Por último, las preposiciones que más se prestan a la creación y combinación de binomios son por y con, visto su carácter casual y de adicción, respectivamente, si bien se pueden encontrar juntas «por sí mismos o con asistencia» (art. $1263 \mathrm{CC}$ ). 
En el plano léxico, analizando la etimología de los ejemplos proporcionados anteriormente para el caso italiano y español con el objetivo de confirmar los residuos lingüísticos existentes en el actual lenguaje jurídico, nos damos cuenta del fuerte sustrato del latín en ambos idiomas.

TABLA 4. Etimología de los binomios en italiano y español

\begin{tabular}{|c|c|}
\hline BINOMIO EN ITALIANO & ORIGEN LINGÜÍSTICO \\
\hline Termini e forme & $\begin{array}{l}\text { Termĭnus (lat.) / } \\
\text { formare (lat.) }\end{array}$ \\
\hline Dichiara o attesta & $\begin{array}{c}\text { Declarare (lat.) / } \\
\text { attestari (lat.) }\end{array}$ \\
\hline Espressa o tacita & $\begin{array}{l}\text { Express (fr./ingl.) / } \\
\text { tacēre (lat.) }\end{array}$ \\
\hline $\begin{array}{c}\text { Pubblicamente } \\
\text { o intenzionalmente }\end{array}$ & $\begin{array}{l}\text { Publǐcus (lat.) / } \\
\text { intendĕre (lat.) }\end{array}$ \\
\hline Con dolo o con colpa & Dolus (lat.) /culpa (lat.) \\
\hline Binomio en español & Origen lingüístico \\
\hline Riesgo e incumplimientos & $\begin{array}{c}\text { Resecāre (lat.) / } \\
\text { complementum (lat.) }\end{array}$ \\
\hline Donar o permutar & $\begin{array}{l}\text { Donāre (lat.) / } \\
\text { permutāre (lat.) }\end{array}$ \\
\hline Excesivos y desproporcionados & $\begin{array}{c}\text { Excedĕre (lat.) / } \\
\text { proportio, -ōnis (lat.) }\end{array}$ \\
\hline Total o parcialmente & Totalis (lat.) / partiālis (lat.) \\
\hline Por la ley o por la voluntad & $\begin{array}{c}\text { lex, legis (lat.) / } \\
\text { voluntas, -ātis (lat.) }\end{array}$ \\
\hline
\end{tabular}

Como se puede observar con cierta claridad, tanto en español como en italiano por influencia del derecho romano, el latín cubre la terminología de gran parte de ellos, y si bien el italiano posee por ser la lengua predilecta un mayor número de italianismos crudos en el lenguaje jurídico (véanse quorum o hit et nunc, entre muchos), no hemos detectado binomios o multinomios compuestos por los mismos.
Por otra parte, para analizar atentamente el plano semántico de sus elementos debemos «prestar atención a la figuratividad, la antonimia, la sinonimia, la co-hiponimia, la pertenencia al mismo dominio semántico, etc.» (Luque Nadal 2017: 170). En nuestro análisis, encontramos casos de sinonimia (art. $83 \mathrm{CP}$ «excesivos y desproporcionados» y art. $336 \mathrm{CCI}$ «argomenti e temi»); de antonomia o pares opuestos (art. 155 CPI «espressamente o tacitamente» y art. 460 CC «oneroso o gratuito»); de hiponimia (art. 301 CP "total o parcialmente” y art. 420 CP "danneggiare o distruggere") y de pertenencia al mismo nivel semántico (vuelvan a verse a tal propósito estos ejemplos). En cuanto a la figuratividad, no hemos encontramos casos en los que el binomio tenga un corte figurado, como pudiera ser en la lengua común el binomio "de sol a sol", sino que todos mantienen una literalidad propia de la exactitud que recoge el lenguaje jurídico.

Por último, los binomios y multinomios no están exentos de sufrir las consecuencias de la proximidad léxica, pues los falsos amigos parciales también imperan con frecuencia en el campo legal. Rescatando los términos expuestos en las tablas, nos damos cuenta de que contraffazione no tiene el mismo significado que su traducción literal 'contrafacción', pues mientras que el concepto italiano indica falsificación o imitación, el español significa 'infracción' y aparece clasificado como en desuso (DRAE, 2014), si bien se puede entender como un hiperónimo del anterior. Contravvenzione, por su parte, no encontraría respuesta directa en 'contravención', ya que significa 'infracción, vulneración de una norma' (DEJ, 2016), mientras que en italiano indica un tipo de delito, ya que reato se divide en dos categorías y una de ellas es la contravvenzione, para la que se prevé el arresto 5 . Otro ejemplo de falso cognado parcial lo representaría el art. $51 \mathrm{CC}$, que recita «mediante acta o expediente», pudiendo significar este último término en italiano tanto fascicolo como la documentación de la investigación (inchiesta).

5 Esto nos lleva, sin duda alguna, a la importancia de la consulta de textos paralelos, pues en nuestra búsqueda hemos encontrado en el CPI 123 entradas para el término contravvenzione, mientras que 'contravención' solo cuenta una presencia en el CP, postulándose como mejor traducción 'infracción', que aparece en 75 ocasiones. 


\section{LA (IN)TRADUCIBILIDAD DEL PROTOTEXTO AUDIOVISUAL}

Entreculturas 11 (2021) pp. 120-130

\section{CONCLUSIONES}

El presente artículo se ha realizado con el fin de aportar un número significativo de unidades fraseológicas especializadas en la combinación italiano-español, pues desgraciadamente en este par de idiomas el camino es largo y solo se encuentran escasos estudios exhaustivos en el campo legal. Este acervo teórico nos ha ofrecido además la posibilidad de realizar un estudio descriptivo y comparativo de algunos de los binomios y multinomios detectados en el Código Penal y en el Código Civil italiano y español. En los códigos normativos, el grado de fijación de la fraseología es elevado y su uso sistemático no es baladí en un lenguaje muy estructurado como el jurídico, en donde premia la forma, la precisión y la univocidad.

En cuanto a los binomios y multinomios, hemos podido observar con cierta regularidad cómo el latín cubre la terminología de gran parte de ellos por influencia del Derecho romano y cómo la dificultad de traducción de los binomios reside en traspasar el espectro lingüístico-cultural de un sistema a otro respetando las mismas características de la lengua de origen. Esta dificultad se agrava aún más en el proceso traductor no solo por las diversas características que poseen, sino también por la falta de equivalencia entre sistemas legales, que representan la expresión más arcaica de una sociedad. Los más recurrentes que hemos encontrado son los formados por sustantivos, verbos y adjetivos, que justificamos en la búsqueda incesante del lenguaje de las leyes de abarcar todas las casuísticas jurídicas con la consecuencia directa de otorgar a las frases una extensión considerable. Más concretamente, los formados por sustantivos han desempeñado mayoritariamente función de sujeto, los formados por verbos han demostrado ser pocos, pero extensos, llegando incluso a recoger en un mismo enunciado cinco verbos y los formados por adjetivos, por su parte, han calificado las acciones en ocasiones de forma ambigüa como en «dannose o pericolose», «significativi e misurabili» o «estese o significative». A este propósito, cabe mencionar cómo estos conceptos son la mera deposición en el Código Penal y Civil de indicadores ambiguos y variables en el tiempo, pues ambos matices dan muestra de la predilección por parte del derecho de preservar este tipo de adjetivos que muestran una cierta indeterminación temporal.

\section{REFERENCIAS BIBLIOGRÁFICAS}

Andrades, Arsenio. (2013). La importancia de los binomios en la traducción jurídica. En Emilio Ortega Arjonilla (Ed.), Translating culture vol. 3 (p. 401-414). Granada: Comares.

Belvedere, Andrea. (2016). Scritti giuridici. Linguaggio e metodo giuridico. Milán: CEDAM.

Código Civil. Gaceta de Madrid, núm. 206, de 25 de julio de 1889.

Codice Civile. (2006). Ebook Altalex.

Código Penal. BOE núm. 281, de 24 de noviembre de 1995.

Codice Penale. (2006). Ebook Altalex Corpas, G. (1998). Criterios generales de clasificación del universo fraseológico de las lenguas, con ejemplos tomados del español y del inglés. Manuel Álvar y Gloria Corpas Pastor (Eds.), Diccionarios, frases, palabras (pp. 157-187). Málaga: Servicios de Publicaciones de la Universidad de Málaga.

Codice di Procedura Penale. Decreto del Presidente della Repubblica 22 settembre 1988, núm. 447.

Del Río Zamudo, Sagrario. (2018). Fraseología jurídica en 29 sentencias y 2 autos españoles. Rivista Internazionale di Tecnica della Traduzione,(20),59-72. Disponible en https:// www.openstarts.units.it/bitstream/10077/23189/3/5_ Ritt_20-2018_interni.pdf

Frago, Juan Antonio. (1989). El marco filológico del Vidal Mayor. En Vidal Mayor. Estudios, Huesca, Excma. Diputación Provincial, pp. 835-112.

González Vallejo. (2020). Lenguaje jurídico comparado: análisis y traducción de los delitos medioambientales del Código Penal italiano. Roma: Aracne.

Gotti, Maurizio. (1991). I linguaggi specialistici. Caratteristiche linguistiche e criteri pragmatici. Florencia: La Nuova Italia.

Gustafsson, Marita. (1975). Binomial Expressions in Presentday English: A Syntactic and

Semantic Study. Turku: Yliopisto.

Kjaer Anne Lise. (2007). Phrasemes in legal texts. H. Burger et al., Berlin (Eds.) Phraseologie / Phraseology. Ein interna- 


\section{Rubén González Vallejo}

Entreculturas 11 (2021) pp. 120-130

tionales Handbuch zeitgenössischer Forschung / An International Handbook of Contemporary Research (pp. 506-516). Berlin/New York: Walter de Gruyter.

Ley Orgánica 9/2011. BOE núm. 180, 28 de julio de 2011

Sentencia 126/2019. BOE núm. 293, 6 de diciembre d 2019.

Luque Nadal, Lucía. (2017). Aspectos fraseológicos y culturales de los co-compuestos o binomios léxicos. Language Design, (19), 149-204. Disponible en http://elies.rediris.es/ Language_Design/LD19/LD19_06_LUQUE_NADAL.pdf

Macías, Elena. (2013). Las expresiones binomiales en el lenguaje jurídico y su traducción en el aula de terminología (españolinglés/francés). Paremia, (22), 209-225. Recuperado de https://cvc.cervantes.es/lengua/paremia/ pdf/022/019_macias.pdf

Macías, Elena. (2015). La traducción de fraseologismos jurídicos en clase de Terminología (francés- español). G. Conde Tarrío, P. Mogorrón Huerta, M. Martí Sánchez y D. Prieto García-Seco (coords.), Enfoques actuales para la traducción fraseológica y paremiológica: ámbitos, recursos y modalidades (pp. 213-237). Madrid: Instituto Cervantes.

Malkiel, Yakov. (1959). Studies in irreversible binomials. Lingua, 21, 142-155.

Mortara Garavelli, B. (2001). Le parole e la giustizia. Divagazioni grammaticali e retoriche su testi giuridici italiani. Turín: Einaudi editore.

Koike, Kazumi. (2001). Colocaciones léxicas en el español actual: Estudio formal y léxico-semantico. Madrid: Universidad de Alcalá/Takoshoku.

Ortíz, Adriana María. (2012). Las locuciones y sus variantes en el diccionario descriptivo del valle de Aburrá. Lingüistica y Literatura, (62), 87-104. Recuperado de https://dialnet.unirioja.es/descarga/articulo/4235854.pdf

Quiroga, Paula. 2006. Fraseología italo-española. Aspectos de lingüistica aplicada y contrastiva. Granada: Granada lingüística.

Real Academia Española. (2014). Diccionario de la lengua española. Espasa, Madrid.

Real Academia Española. (2016). Diccionario del español jurídico. Espasa: Madrid.

Sciutto, Virginia. (2005). Unidades fraseológicas: un análisis contrastivo de los somatismos del español de Argentina y del italiano. AISPI. Actas xxiii, 502-518. Recuperado de https://cvc.cervantes.es/literatura/aispi/pdf/22/II_31.pdf Sentenza Cassazione Civile sez. I. núm. 1841 del 26/01/2011. Sevilla, Julia. (1993). Las paremias españolas: clasificación, definición y correspondencia francesa. Paremia, (2), 15 20. Recuperado de https://cvc.cervantes.es/lengua/paremia/pdf/002/001_sevilla.pdf

Tabares, Encarnación. (2016). Fraseología jurídica y variación topolectal. Onomázein, (33), 1-15. Recuperado de http:// onomazein.letras.uc.cl/Articulos/N33/33_1_Tabares.pdf

Toledo, María Cristina, Martínez, Raquel. (2018). Colocaciones, locuciones y compuestos sintagmáticos bilingües (español-francés) sobre diabetes en el corpus comparable Cordiabicom. Panace@, 19, (47), 106-114. Recuperado de https://dialnet.unirioja.es/servlet/ articulo? codigo $=6629816$

Vázquez y del Árbol, Esther. (2006). La traducción al español de las expresiones binomiales y trinomiales (Doublet \& Triplet Expressions) en inglés jurídico: El caso de los Testamentos (Wills). BABEL-AFIAL, (15), 1926. Recuperado de https://dialnet.unirioja.es/servlet/ articulo? codigo $=5651107$ 